\title{
ANALISE DA IMPORTÂNCIA DE MEDIDAS DE SEGURANÇA CONTRA INCÊNDIO EM RESIDÊNCIAS UNIFAMILIARES
}

\author{
Emiliano Colferai Carnieletto ${ }^{I}$ \\ Michele Giovanoni de Castro ${ }^{2}$ \\ Rogério Lima Araújo3
}

\section{RESUMO}

Os estudos em prevenção contra incêndio estão aumentando de forma lenta e cada dia mais é necessário maneiras eficazes priorizando a proteção da vida dos ocupantes das edificações. Esse trabalho tem como objetivo analisar a incidência desse tipo de ocorrências no âmbito residencial, não somente de edificações multifamiliares como em unifamiliares trazendo como informações a norma de outros países mais desenvolvidos onde as normas e leis nesses casos são mais rígidas e abrangentes. Outro assunto tratado é trazer algumas medidas de segurança que podem ser adaptadas para nosso país que são cobradas nessas normas, entre elas a detecção e alarme de incêndio e os acessos e saídas para emergência. A análise feita em gráficos de ocorrência de incêndio nos Estados Unidos nos mostra a eficácia das leis de incêndio em função da quantidade de incêndio. Os estudos de ocorrência de algumas regiões do estado do Paraná nos últimos 10 anos trazem estatísticas alarmantes sobre a quantidade de incêndios em edificações serem residenciais. Então se torna necessário um maior cuidado ao projetar residências, assim como a tentativa de reduzir esses números de ocorrências.

Palavras-chave: Proteção; Incêndio; Residências.

\footnotetext{
${ }^{1}$ Engenheiro Civil e pós-graduado em Engenharia e Gestão e Prevenção Contra Incêndio e Pânico no Centro Universidade Gugacz. Email: emiliano.colferai94@gmail.com

2 Engenheira Civil e pós-graduada em Engenharia e Gestão e Prevenção Contra Incêndio e Pânico no Centro Universidade Gugacz. Email:mi_giovanoni@hotmal.com

3 Oficial Bombeiro Militar e Graduado em Física pela Universidade Federal do Paraná. Email: araujobm@yahoo.com.br
} 


\title{
ANALYSIS OF THE IMPORTANCE OF FIRE SAFETY MEASURES IN UNIFAMILIARY RESIDENCES
}

\begin{abstract}
Fire prevention studies are increasing slowly, and more and more effective ways of protecting the life of occupants of buildings are needed. The objective of this study is to analyze the incidence of this type of occurrence in a residential setting, not only in multifamily buildings, but also in unifamiliary ones, bringing information as the norm of other more developed countries where the norms and laws in these cases are more rigid and comprehensive. Another issue addressed is to bring some security measures that can be adapted to our country that are charged in these standards, among them the detection and fire alarm and the accesses and exits for emergency. The analysis done in fire charts in the United States shows us the effectiveness of fire laws as a function of the amount of fire. The studies of the occurrence of some regions of the state of Paraná in the last 10 years bring alarming statistics on the amount of fires in residential buildings. Therefore, greater care is required when designing homes, as is attempting to reduce these numbers of occurrences.
\end{abstract}

Keywords: Protection; Fire; Residences.

Artigo Recebido em 21/12/2018 - Aceito em 27/02/2019 - Publicado em 31/03/2019 


\section{INTRODUÇÃO}

Quando se fala em incêndio, no âmbito geral, se faz após a sua ocorrência e geralmente buscando um culpado ou responsável por ele, seja em grandes ou pequenas construções. Pouco é, em nossa cultura, falado e orientado em função da prevenção de incêndio ou ações que minimizem os efeitos da ocorrência dos mesmos em seus momentos iniciais, sem que pareça uma obrigação regulamentada. Nos dias de hoje é de suma importância visão para a população da seriedade de formas de prevenção de incêndios em geral, não como uma necessidade a qual é obrigatória pelos órgãos competentes, e sim da consciência e visão de que é um risco, o qual ocorre não somente perdas materiais, mas por vezes perdas de vidas.

O estudo de Gestão e Prevenção Contra Incêndio e Pânico é uma área da engenharia que consiste em estabelecer critérios para a análise das situações de risco as quais estão presentes diariamente na vida das pessoas, sendo assim, deve-se procurar maneiras de evitar esses perigos de maneira eficiente, ou erradica-los assim que possível em casos de ocorrência.

Partindo do princípio que os incêndios são possíveis riscos que estão presentes no dia a dia, a principal analise que deve ser feita é no sentido de quais locais são mais propícios a terem esse tipo de situação. As principais normas regulamentadoras desse tipo de risco dizem respeito a edificações com fins comerciais e industriais, sendo pouco abrangente no âmbito residencial.

Segundo os dados estatísticos do Corpo de Bombeiros do Paraná (SYSBM), o maior número de ocorrências de incêndio se dão em âmbito residencial, dessa forma este trabalho busca um método para a redução deste tipo de ocorrência, ou mesmo de melhorar o tempo de resposta do Corpo de Bombeiros local, através da instalação de determinadas exigências as quais venham a ser benéficas para a segurança da população em suas residências.

Em outros países os quais possuem uma legislação de prevenção de incêndios mais antiga e mais completa pode-se perceber que o uso de diversos 
métodos de prevenção que geram resposta imediata para esse tipo de ocorrência em locais de risco elevado em residências, inclusive unifamiliares, sendo eficazes e comuns. Isso nos traz a análise de vários fatores, os quais pode-se citar: qual a quantidade de ocorrências anual em edificações residenciais, o que a norma Brasileira nos traz de tipos de prevenção nesse tipo de edificação e quais as soluções para que haja uma diminuição de casos de incêndio em residências.

\section{DESENVOLVIMENTO}

Segundo Mitidieri (2008), as consequências dos incêndios na sociedade são enormes. Ocorrem perdas sociais, econômicas e humanas. Sendo assim os incêndios em edificações são ocorrências que devem ser constantemente estudadas, assim como suas medidas de prevenção e controle. A evolução da ciência de prevenção de incêndio foi adequada durante a passagem dos anos e a cada dia mais são necessárias atualizações em leis e normas para adequação devido as diferentes situações vividas em cada nova ocorrência.

A Prevenção de incêndio é o conjunto de medidas que visam: evitar o incêndio; dificultar a propagação do incêndio; proporcionar meios de controle e extinção do incêndio, entre outros (CSCIP, 2015). Ou seja, é necessário a análise das possíveis causas e efeitos e assim poder formular e produzir soluções para as mesmas.

A NBCC (2010) define que a segurança contra incêndio tem o objetivo de reduzir a probabilidade de que uma pessoa em ou um edifício próximo seja exposto a um incêndio devido à ineficiência de um projeto ou da construção de uma edificação.

Segundo a NBR 17240 (2010), a adequada proteção de determinadas áreas ou equipamentos será possível somente após analises corretas de todas as particularidades da edificação podendo assim empregar componentes adequados para cada tipo de utilização. Cada tipo de edificação tem suas 
características específicas, e somente após um estudo detalhado, é possível definir quais os tipos de detecção e combate a incêndio mais adequado para aquela situação.

As medidas de prevenção e controle dependem de diversos fatores, estando relacionados à edificação como os materiais que ela contém, sua carga incêndio, a localização, o tipo de ocupação, a área existente, entre outras.

Segundo Correa et al (2015) aferir e analisar os incêndios em edifícios no Brasil, mapeando suas localizações, peculiaridades construtivas, tipo de ocupação, estimando o local dos focos primários, a população fixa e flutuante, as cargas incêndios consumida e existente, pode contribuir consideravelmente na implantação de políticas públicas de minimização do problema.

O Brasil é um país relativamente novo nos estudos de ciência e prevenção de incêndios, e ainda peca muito em investimentos e pesquisa nessa área, assim como algumas normas específicas apesar de estarem corretas, ainda deixam a desejar no quesito de proteção, assim podemos tomar como base algumas normas norte-americanas para o estudo de tais ocorrências.

O NFPA (2017) nos traz a necessidade de códigos para construções em geral e que os códigos são adotados e aplicados pelos órgãos responsáveis para fornecer um nível mínimo de segurança de proteção aos ocupantes da edificação e a propriedade. Suas intenções são proteger contra os riscos associados à sua utilização e reduzir a probabilidade de ferimentos ou morte por incêndio, falha estrutural ou má utilização.

Segundo a NBCC (2010) embora a probabilidade de mortes ou feridos em um incêndio não poderem ser completamente eliminados, a segurança contra incêndio em uma edificação deve contar com recursos comprovados de projeto de construção destinados a minimizar o risco de danos a pessoas em casos de incêndio da melhor forma possível. Projetar um prédio para garantir um risco mínimo ou cumprir um nível prescrito de segurança do fogo é mais 
Revista Científica do Corpo de Bombeiros Militar de Pernambuco

Artigo publicado no Vol.05 º12 - Edição de JAN a JUN 2019 - ISSN 2359-4829

Versão on-line disponível em: http://www.revistaflammae.com.

complexo do que apenas a simples consideração de quais materiais construção serão utilizados na construção. Muitos fatores devem ser considerados incluindo qual será a utilização do edifício, o número de ocupantes, quão facilmente eles podem sair do prédio em caso de incêndio e como o fogo pode ser contido.

Variados são os fatores os quais devem ser analisados quando se trata da segurança de incêndio, a utilização da edificação define diretamente o risco a qual a mesma está exposta, assim como o seu tamanho e vários aspectos arquitetônicos que facilitam ou impossibilitam a evacuação em casos desse tipo de incidentes.

As edificações residenciais são as que as perdas, nas ocorrências de incêndios, são mais significativas e valiosas, quando se trata não só de perdas materiais, os quais são de grande valia para diversas pessoas, assim como a ocorrência de vítimas fatais, que nos traz, principalmente esse cuidado para com as medidas as quais podemos tomar para a prevenção de acidentes com fogo.

Sendo que historicamente podemos identificar vários acidentes envolvendo prédios residenciais, que, como consequência se pode apontar elevadas perdas humanas e importantes prejuízos financeiros. (FREIRE, 2009)

De acordo com a CSCIP (2015), as edificações que estão excluídas das exigências são:

- Edificações de uso residencial exclusivamente unifamiliares;

- Residências exclusivamente unifamiliares localizadas no pavimento superior de ocupação mista com até dois pavimentos, e que possuam acessos independente;

É necessário, principalmente, analisar que, segundo Carlo (2008):

As incidências, mais frequentes, de incêndios tanto pequenos como grandes são nas edificações. Alguns exemplos de início de ignição são: vazamento de gás de bujões com explosões, curto-circuitos em instalações elétricas por excesso de carga, manuseio de explosivos e outros produtos perigosos em locais não adequados, esquecimento de ferro de passar roupa, fogões e eletrodomésticos ligados, etc. Toda tragédia de incêndio começa pequena. 
Então, a análise feita sobre os incêndios em edificações nos trazem causas que ocorrem mais frequentemente em edificações residenciais, os quais além de ser necessário o maior controle. Em países mais desenvolvidos inclusive, na área de prevenção de incêndio e pânico, a taxa de ocorrência é relativamente alta para esses tipos de edificação, sendo então necessário, não somente minimizar a quantidade de ocorrências, assim como a proteção dos ocupantes das edificações.

Os Estados Unidos da América (EUA) registraram 1,6 milhões de incêndios em 2005 com 3677 mortes, sendo que 83\% dessas mortes ocorreram em incêndios em residências (CORREA et al., 2015 apud SEITO et al., 2008).

Para Coughi (2006) no Brasil, as residências unifamiliares estão isentas de qualquer forma de proteção contra incêndio e isto talvez explique 0 fato de elas apresentarem maior quantidade de casos de incêndio.

"Toda a edificação, sob o ponto de vista de segurança, está sujeita a uma calamidade imprevisível: o fogo. O fogo é capaz de causar grandes acidentes e catástrofes, gerando perdas de vidas humanas e enormes prejuízos materiais" (FAGUNDES, 2013)

As fatalidades em incêndios devem ser levadas em consideração quando tratamos de tipos de edificação em que se faz necessário o projeto de prevenção de incêndio, pois é exigido um maior controle em edificações industriais, comerciais ou multifamiliares e não sendo exigido nenhum tipo de controle e cuidado em residências unifamiliares aqui no Brasil.

Segundo Freire (2009), incêndio se caracteriza pela destruição pelo fogo, e desde que o homem descobriu como produzir e controlar o fogo, vem utilizando-o para diversas funções importantes na sobrevivência humana trazendo inovações e tecnologias. Mas, ao mesmo tempo em que havia o aumento da tecnologia, houve consequentemente o aumento gradativo de incêndios ocorridos nos últimos anos. 
Sendo o incêndio o fogo fora de controle, deve-se entender também qual a dinâmica do fogo em diversas situações e assim fazer uma melhor analise de quais as suas causas e melhores tipos de detecção e maneiras para prevenção e resposta imediata para evitar que se alastres pela residência, causando maiores perdas.

O fogo é uma reação de combustão química exotérmica entre os diversos tipos de combustíveis e o oxigênio, geralmente resultando de um processo rápido, e com uma temperatura de reação alta (COUGHI, 2006).

E estudar a dinâmica e o comportamento do fogo nos permite ampliar nossos estudos para encontrar maneiras não somente de prevenção e instalação de alarmes por exemplo, como também, para as primeiras respostas nos casos de ocorrência do mesmo, como a utilização de extintores entre outras ações.

Sendo o fogo uma reação exotérmica, é afastada a ideia de que o fogo só exista onde existe a chama original, pois pela transmissão do calor, vários focos podem surgir em diferentes pontos da edificação (FREIRE, 2009).

Assim sendo, após a existência do fogo em qualquer ambiente, sendo ela caracterizada como a fonte de ignição, desde que exista materiais combustíveis e oxigênio, a sua propagação ocorre de forma rápida e eficaz.

Para que haja fogo, é necessário que ocorra simultaneamente o encontro de três elementos essenciais: o material combustível, o comburente (comumente o oxigênio) e uma fonte de calor, criando assim o triângulo do fogo (FAGUNDES, 2013), como mostrado na Figura 1. 
Figura 1 - Triangulo do fogo.

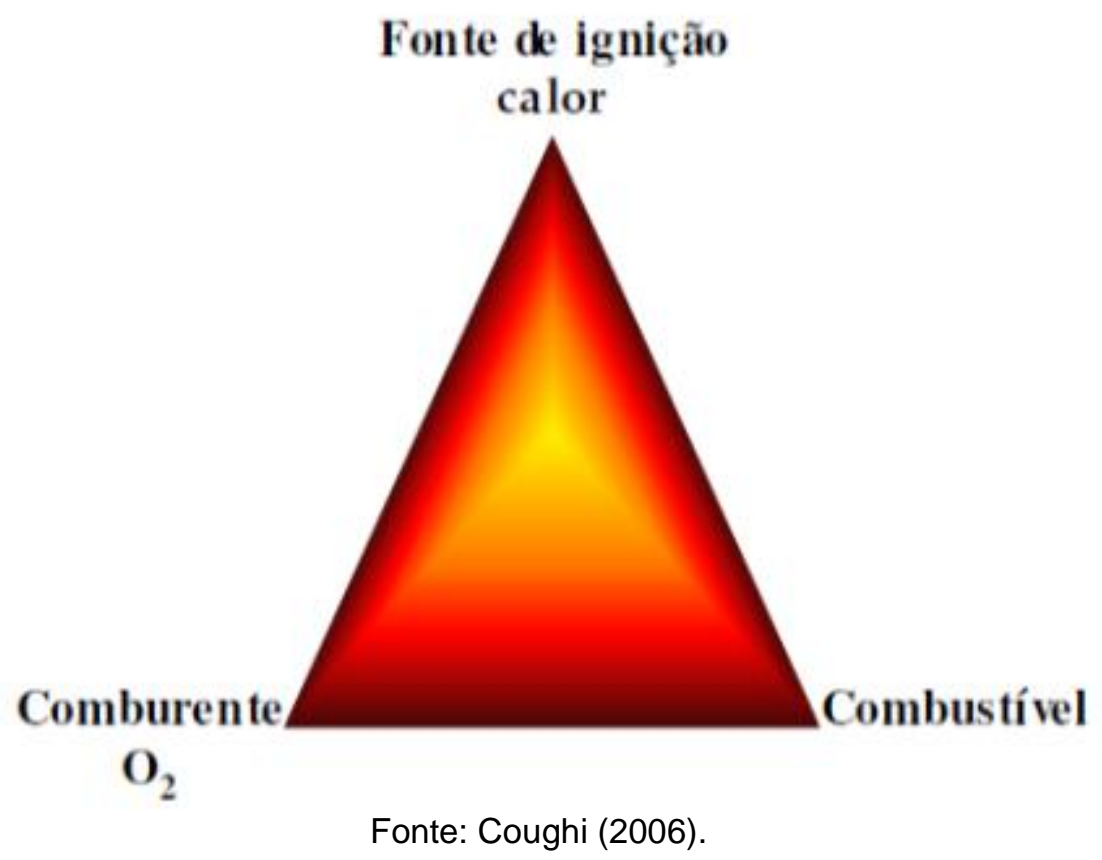

Sendo assim, nenhum incêndio é iniciado sem a combinação desses três elementos, os quais devem ser estudados para que, ao fazer qualquer tipo de construção, possamos tomar cuidados para evitar que haja esse contato, e ocasione os focos de incêndio.

Nesse triângulo, combustível é definido como elemento que serve de campo de propagação do fogo, por exemplo madeira, papel, óleo, gases, entre outros. Já o comburente é o elemento que ativa e intensifica o fogo, como 0 oxigênio. A fonte de ignição, que é o calor, que mantém e incentiva a propagação do fogo (FREIRE, 2009)

Essa análise permite o estudo de melhores maneiras de evitar a propagação do fogo para outros compartimentos, ajustando assim os melhores tipos de materiais para cada local.

Segundo Gomes (2014), o incêndio inicia-se bem pequeno e seu crescimento dependerá dos materiais disponíveis e sua distribuição no ambiente, observando-se assim que, independentemente do tamanho final do incêndio, ele começa de maneira pequena e está diretamente ligado, além de 
outros fatores, do tipo de ocupação da edificação e dos materiais que ela contém.

Para Freire (2009):

Toda dinâmica do fogo é fortemente influenciada pela atividade humana e pelo desempenho das edificações. A continua combinação do material combustível (papeis, tecidos, gases, madeira, líquidos inflamáveis, isopor) com o oxigênio gera uma reação exotérmica. (...) Toda vez que os combustíveis, em presença do oxigênio, encontram calor, (...) em quantidade o suficiente para combustão, haverá a chama.

Um dos fatores fundamentais nos inícios e continuações das ocorrências de incêndios é o comportamento humano, sendo em falhas de projetos e instalações das edificações, em negligência na utilização da ocupação ocasionados acidental ou intencionalmente. Sendo esses motivos aliados as reações químicas e o oxigênio participam ativamente tanto na ignição quanto no crescimento do incêndio.

"Compreender a lógica e a dinâmica do incêndio em edificação no Brasil, estabelecendo modelos e padrões, fortalecerá as bases da legislação contra incêndio" (CORREA et al, 2015)

Quando estudamos as possíveis causas dos incêndios, é necessário analisar o porquê, como e onde foi a ignição dos focos de incêndio e se é originaria da ação do homem ou não. As possíveis causas, segundo Fagundes (2013), são:

Causas humanas (culposas e criminosas): A causa humana culposa é causada pela ação direta do homem por negligência, imprudência ou imperícia. (...) A causa criminosa se identifica quando o homem, por motivos psicológicos e materiais, voluntariamente, provoca um incêndio ou explosão. É o chamado incendiarismo. (...) Também, por motivos psicopáticos o homem pode provocar um incêndio. São os chamados piromaníacos, que provocam incêndios com o intuito mórbido de se emocionar com o espetáculo apresentado pelas chamas.

Causas naturais: Ocorrem pelos chamados fenômenos naturais, tais como raios elétricos, descargas atmosféricas, terremotos, erupções vulcânicas, desabamentos, o sol (através da concentração de seus raios em vidros e lentes); cujo controle foge dos procedimentos preventivos.

Causas acidentais (elétricas, mecânicas e químicas): são as que ocorrem devido às falhas ocasionais, mesmo que o homem tenha tomado às devidas precauções para que isso não ocorra, entretanto, devido a inúmeros fatores independentes da sua vontade, eles acontecem. (...) 
Causas industriais: o risco de incêndios industriais vem aumentando devido à utilização de novos materiais e projetos de edificações, além do grande consumo de energia, onde uma das fontes de energia é a calorífica. Com a Revolução Industrial, os países que implantaram parques industriais observaram 0 crescimento assustador dos casos de incêndios, principalmente nos centros urbanos criados para atender a demanda de mão-de-obra para as indústrias.

As causas relacionadas a ação do homem podem ser por diversos fatores, e não somente na área industrial ou comercial, a área residencial em ocupações unifamiliares são tão suscetíveis a ocorrência de incêndio devido a quantidade de tempo gasto em suas residências, e também por sua rotina.

Muitos dos focos de incêndio são iniciados devido a falha humana tanto por ignorância ou descuido ao realizar funções cotidianas como por exemplo, na utilização de fogões para cozinhar, ao realizar um reparo na rede elétrica sem os devidos cuidados, ao deixar de fazer a manutenção dos cabos e instalações existentes, assim como ignorância na utilização da rede elétrica da edificação.

Os sistemas de segurança contra incêndios podem ser preventivos, que tem como principal objetivo prevenir a ocorrência de incêndios e reduzir a propagação e podem ser na área de proteção, e está relacionada aos materiais utilizados, as rotas de fugas e os sistemas de detecção dos incêndios.

A NBCC (2010) traz:

Prevenir a ignição é a primeira linha de defesa em segurança contra incêndios. A segunda linha de defesa, se a ignição ocorrer, é gerenciar o impacto do fogo e minimizar o risco. Os dois principais métodos para gerenciar o impacto de um incêndio são gerenciar as pessoas expostas e gerenciar o fogo em si. Gerenciar as pessoas expostas significa garantir os ocupantes fora do edifício e longe do perigo antes de serem feridos. A maioria das lesões ou mortes são causada pelos vapores tóxicos da fumaça por isso é importante que as pessoas sejam alertadas para o fogo rapidamente e, em seguida, que possam sair do perigo ao sair da construção.

As normas norte-americanas, assim como as leis no Brasil, nos trazem a necessidade de existir em edificações, diversas formas preventivas de incidentes com fogo. Para cada tipo de edificação, muda também as exigências, as quais para pequenas residências e residências unifamiliares geralmente contam com detectores de fumaça e saídas de emergência. 
Revista Científica do Corpo de Bombeiros Militar de Pernambuco

Artigo publicado no Vol.05 Nº12 - Edição de JAN a JUN 2019 - ISSN 2359-4829

Versão on-line disponível em: http://www.revistaflammae.com.

Existem inclusive livros e sites em algumas cidades, como por exemplo Ontário, no Canadá onde as leis específicas para a prevenção de incêndios em residências estão disponíveis em sites. Essas informações, além de serem de fácil acesso, estão associadas com orientações úteis para toda a população, a qual conta com educação sobre esse tipo de ocorrência para adultos e crianças.

O Fire Department (2018) de Ontário, Canadá, divulga diversas informações sobre a segurança contra incêndios, por exemplo, como realizar as instalações de detectores de fumaça, o que fazer em caso de ocorrência de incêndio, como se proteger da fumaça, entre outras informações relevantes nesse tipo de situação.

Esse tipo de informação, em conjunto com uma cultura de medidas de segurança, pode trazer uma diminuição considerável da quantidade de ocorrências e vítimas. Para a NBCC (2010)

Gerenciar o fogo envolve medidas destinadas a limitar a propagação e severidade do fogo. Em edifícios menores isso pode ser tão simples quanto garantir que haja um extintor de incêndio disponível. Os Códigos de construção exigem instalações ou sistemas de construção que se destinam a limitar a exposição de pessoas a fogo, facilitando a sua fuga. Medidas de segurança contra incêndios nesta categoria incluem:

- detectores e / ou sistemas de alarme de incêndio para avisar pessoas e levá-los a evacuar;

- aberturas de janelas e portas para permitir que as pessoas possam escapar ou fornecer acesso para bombeiros para evacuar as pessoas;

- saídas como corredores e escadas para permitir que as pessoas evacuem com segurança.

Isso nos mostra, inclusive a necessidade que outros países demonstram sobre a existência de meios de prevenção para esse tipo de incidente, não somente em indústrias ou locais com maior concentração de pessoas, mas também para residências unifamiliares.

Em Ontário, segundo o FIRE PROTECTION AND PREVENTION ACT (2017), em toda e quaisquer tipo de residência, deve haver alarmes de fumaça em funcionamento. Também deve ser instalado em todos os níveis e próximo aos quartos e testados todo mês, sendo trocada as baterias pelo menos uma vez ao ano. 
Assim como em outras normas, o IRC (2015) trás a necessidade a existência de alarmes de fumaça em todas as novas construções, bem como em alterações ou ampliações de edificações já existentes, os novos cômodos devem estar equipados com esse tipo de dispositivo.

O sistema de detecção tem como conceito principal detectar o fogo em seu estágio inicial, a fim de possibilitar que os ocupantes abandonem de forma rápida e segura a edificação e que haja uma iniciação rápida do combate ao incêndio, evitando que haja perdas de vidas, de patrimônio e a contaminação do meio ambiente. (ARAUJO; SILVA, 2008).

Segundo a NBR 17240 (2010),

A seleção do tipo e do local de instalação dos detectores deve ser efetuada
com base nas características mais prováveis de um princípio de incêndio e
do julgamento técnico, considerando-se os parâmetros: aumento da
temperatura, produção de fumaça, produção de chama, materiais existentes
nas áreas protegidas, forma e altura do teto, ventilação do ambiente,
temperaturas típicas e máxima de aplicação, entre outras características de
cada instalação, conforme requisitos técnicos dos equipamentos.

Os sistemas de detecção e alarme de incêndio são compostos por conjuntos de elementos dispostos planejadamente e interligados de forma que forneçam informações de princípios de incêndios ou de fumaça por meio de indicações sonoras e visuais. Eles detectam o incêndio através de fenômenos físicos como: fumaça, elevação da temperatura do ambiente e radiação da luz de chama aberta. $O$ alarme pode ser acionado por meio de acionadores manuais ou de detectores automáticos (GOMES, 2014 apud UMINSKI, 2003).

Há uma variada quantidade de modelos de detectores disponíveis como sistemas de alarmes automatizados ou manuais. Podem ser constituídos basicamente pelos seguintes componentes: detectores automáticos de incêndio, acionadores manuais, painel de controle (processamento), meios de aviso (sinalização), fonte de alimentação elétrica e infraestrutura (eletrodutos e circuitos elétricos). (ARAUJO; SILVA, 2008)

Segundo Gomes (2014, apud UMINSKI, 2003) os detectores automáticos dividem-se em três grupos basicamente: 
Detectores de fumaça: dispositivo destinado a atuar quando ocorre a presença de gases ou partículas, visíveis ou não, produzidos pela combustão. A área máxima de ação é de $81 \mathrm{~m}^{2}$, para instalação em tetos planos, a uma altura de instalação de até $8 \mathrm{~m}$.

Detectores de temperatura: dispositivo destinado a atuar quando a temperatura ambiente ultrapassa um valor determinado. A área máxima de ação é de $36 \mathrm{~m}^{2}$, para instalação em tetos planos, a uma altura de instalação de até $7 \mathrm{~m}$.

Detectores de chama: dispositivo destinado a atuar em resposta a uma radiação visível ou não. Sua instalação deve ser executada de forma que seu campo de visão seja suficiente e não impedido por obstáculos. Os tipos mais utilizados são o detector infravermelho e detector ultravioleta.

Sendo assim, os tipos de detectores são usados em edificações conforme a necessidade do cliente e do bom senso do projetista para análise de qual a melhor solução de utilização.

O IRC (2015) trás também os locais onde devem ser instalados esses alarmes em residências, sendo eles em todos os quartos de dormir, não menos do que $91,4 \mathrm{~cm}$ horizontalmente das portas de banheiros que contenham banheiras ou chuveiros.

As detecções e alarmes de incêndio são eficazes em casos de incêndio para que haja uma resposta rápida do usuário da edificação. Mas também é necessário analisar outros meios para a proteção da vida, principalmente no caso de ocorrência em que o fogo saia de controle. Analisando essas situações, se considera o estudo para que os métodos de evacuação ocorram de maneira eficaz, os quais são de suma importância para que haja a saída de forma correta e em um curto período de tempo, prevenindo assim maiores danos pessoais aos ocupantes da edificação.

Outro meio para a proteção contra incêndio que é aplicado em diversas normas e códigos para construções em outros países, o qual inclusive, não envolve custos de instalação e manutenção são os locais de saídas das residenciais, as quais podem ser utilizadas como saídas de emergência, assim como corredores de passagem e acessos, com larguras mínimas para a evacuação correta e segura.

A NFPA 5000 (2018) traz a necessidade de meios de evacuação em casos de emergência, que para residências com dois cômodos ou mais, em 
todo quarto ou dormitório e toda área de uso comum deve existir, pelo menos, um meio de saída primário e um meio de saída secundário. O meio de saída secundário não é obrigatório quando, no cômodo existir uma saída diretamente para fora em edificações térreas, ou quando o cômodo está protegido por chuveiros automáticos.

Os meios de saída das edificações nos trazem novamente as normas brasileiras, as quais nos orientam a ter diversos cuidados ao executa-las, tanto por suas dimensões, como por seu local de existência e a disposição de moveis que possam, de qualquer maneira, interferir no caminho.

O IRC (2015) são códigos internacionais para construções de residências, e é amplamente utilizado no mundo inteiro, define que meios de saída devem providenciar um caminho, tanto vertical, como horizontal continuo e sem obstrução para o local seguro, fora da residência sem necessariamente passar pela garagem.

A NPT 011 (2016) inclusive define que "os acessos devem permanecer livres de quaisquer obstáculos, tais como móveis, divisórias móveis, locais para exposição de mercadorias, e outros, de forma permanente, mesmo quando o prédio esteja supostamente fora de uso"

Sendo assim, deve-se sempre priorizar a retiradas dos ocupantes em âmbito geral, sem que os mesmos fiquem retidos em locais devido a má distribuição de moveis, ou havendo bloqueios de passagem por quaisquer motivos.

Para ABOLINS (2008) a elaboração de um sistema de saídas de emergência eficiente deve ter como prioridade as condições de dar conforto mínimo e segurança ao usuário. É de suma importância o êxito na retirada de pessoas de locais sinistrados. Em poucos segundos os usuários da edificação são submetidos à um evento em que a carga física e emocional a qual vai estar exposto é incomum e a construção deve prevenir a ocorrência de riscos desnecessários. 
Os acessos e saídas de uma edificação são inevitáveis em quaisquer tipos de edificação, sendo elas: industrias, comércios ou outros serviços aos quais é projetado, esse tipo de preocupação pode ser utilizado também ao projetar residências, sendo unifamiliares, como multifamiliares.

Assim como a NFPA 5000 (2018), o IRC (2015) define diretrizes para larguras mínimas das saídas das residências, que seria de no mínimo $81,3 \mathrm{~cm}$ onde a porta deve abrir $90^{\circ}$ sendo que altura mínima do meio de saída não pode ser menor que 198,1 cm de vão livre. Elas devem prontamente ser abertas por dentro da edificação e não podem ter uma chave especial ou algo que possa dificultar a saída para o exterior da residência.

As dimensões mínimas para saídas de emergência também são definidas na NPT 011 (2016), as quais são dimensionadas em função a população da edificação, sendo, pela quantidade de ocupantes da edificação, as unidades de passagem necessárias.

Sendo assim, essas maneiras de proteção contra incêndios, tanto na detecção dele, como nas saídas de emergência, podem auxiliar na retirada de pessoas das ocupações, priorizando assim a vida dos moradores, não somente de grandes edificações, como também de residências.

Então, para a análise da necessidade de projetos de proteção de vidas e dos tipos prevenção e controle de incêndio para otimizar as a ação do corpo de bombeiros em ocorrências de incêndio em edificações unifamiliares, foi necessário a busca de normas de outros países.

Como podemos ver na Figura 2, coletado de CTIF (2017), os Estados Unidos da América, entre os países analisados por essa pesquisa, é o segundo com maior número de incêndios, nesse caso, 6,1 incidentes a cada 1.000 habitantes, registrados pelo corpo de bombeiros em 2015. 
Revista Científica do Corpo de Bombeiros Militar de Pernambuco

Artigo publicado no Vol.05 Nº12 - Edição de JAN a JUN 2019 - ISSN 2359-4829

Versão on-line disponível em: http://www.revistaflammae.com.

Figura 2 - Número médio de incêndio a cada 1.000 habitantes.

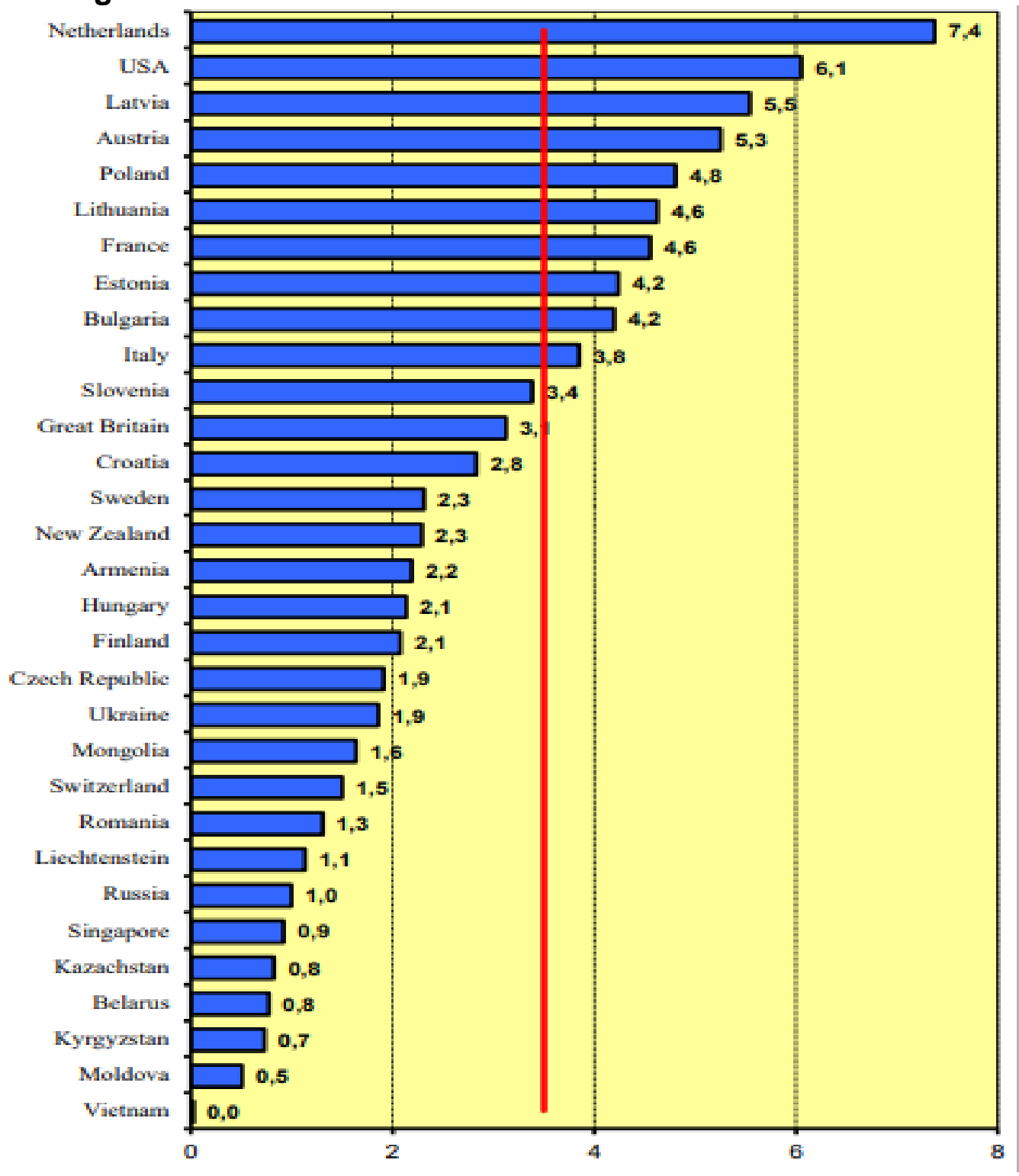

Fonte: CTIF (2017).

Sendo explicado assim alguns dos motivos pelos quais o EUA é um dos países com maiores cobranças em leis para a prevenção de incêndio entre seus estados, pois apesar de cada um ter leis específicas que determinam métodos de construções para residências para uma ou duas famílias, algumas normas são seguidas por todos os estados, inclusive trazendo a necessidade de alarme de incêndio assim como de acessos e saídas de emergência. 


\section{Revista FLAMMAE}

Revista Científica do Corpo de Bombeiros Militar de Pernambuco

Artigo publicado no Vol.05 Nº12 - Edição de JAN a JUN 2019 - ISSN 2359-4829

Versão on-line disponível em: http://www.revistaflammae.com.

A Figura 3, dos dados coletados da CTIF (2017), nos traz informações sobre a quantidade média de mortes a cada 100 casos de incêndio.

Figura 3 - Número médio de mortes a cada 100 incêndios.

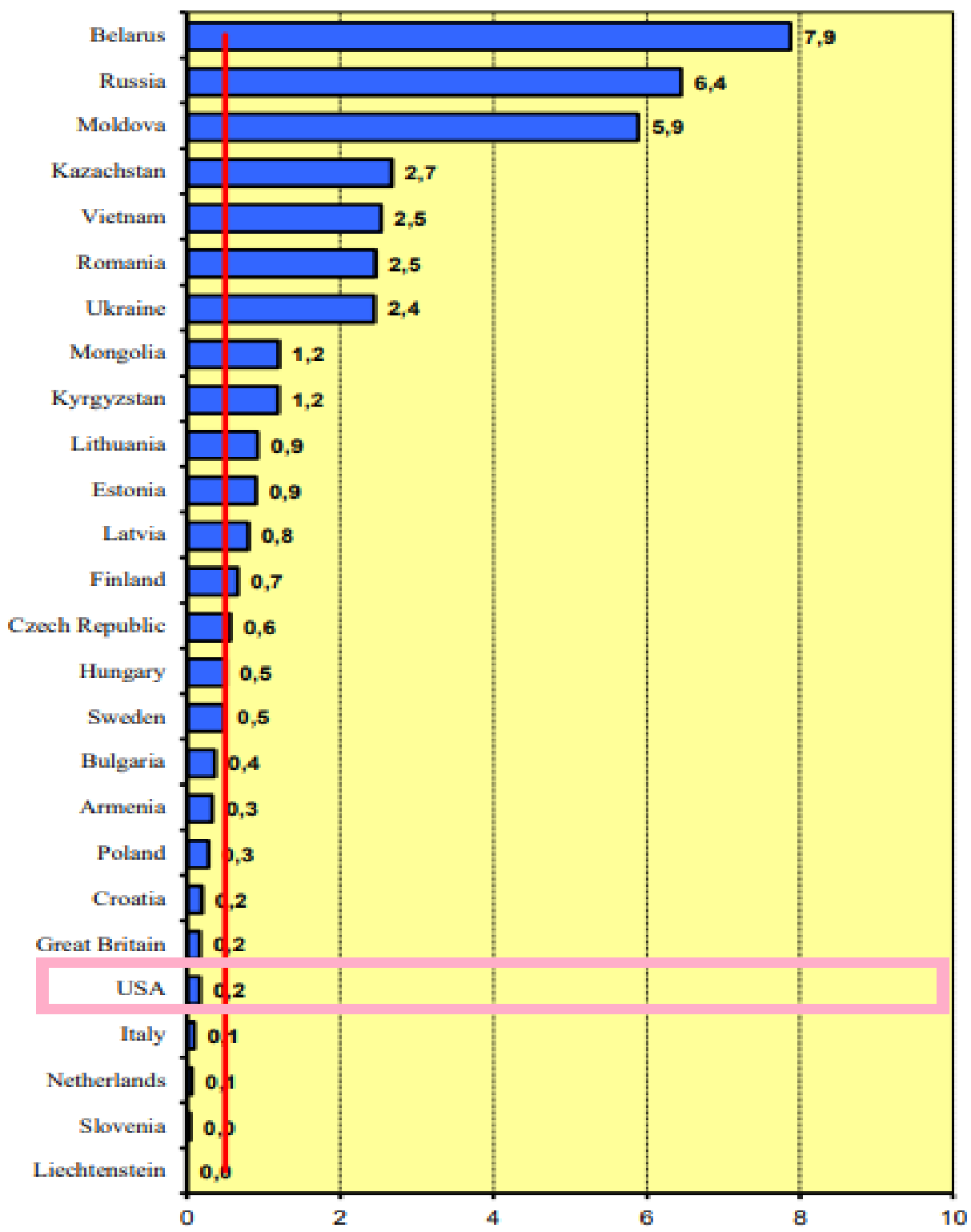

Fonte: CTIF (2017).

Analisando as estatísticas de número de mortes em incêndios com essas informações coletadas, pode-se ver como essas cobranças se tornam eficaz quando, apesar da quantidade alta de incidentes nos Estado Unidos da 


\section{Revista FLAMMAE}

Revista Científica do Corpo de Bombeiros Militar de Pernambuco

Artigo publicado no Vol.05 Nº12 - Edição de JAN a JUN 2019 - ISSN 2359-4829

Versão on-line disponível em: http://www.revistaflammae.com.

América, o número de morte ser relativamente baixo comparado com outros países com menor quantidade de casos e maior numero mortes resultantes destes, como mostrado na Figura 3.

Trazendo esse tipo de análise para nossa atual realidade, a qual nos permite comparar dados do Brasil outros dados analisados são o número de ocorrência de focos de incêndio notificados pelo corpo de bombeiros que ocorreram em locais residenciais do Paraná, onde existem taxas confiáveis desse tipo de ocorrência.

Gráfico 1 - Número de incêndios no Paraná entre 2005 a 2016.

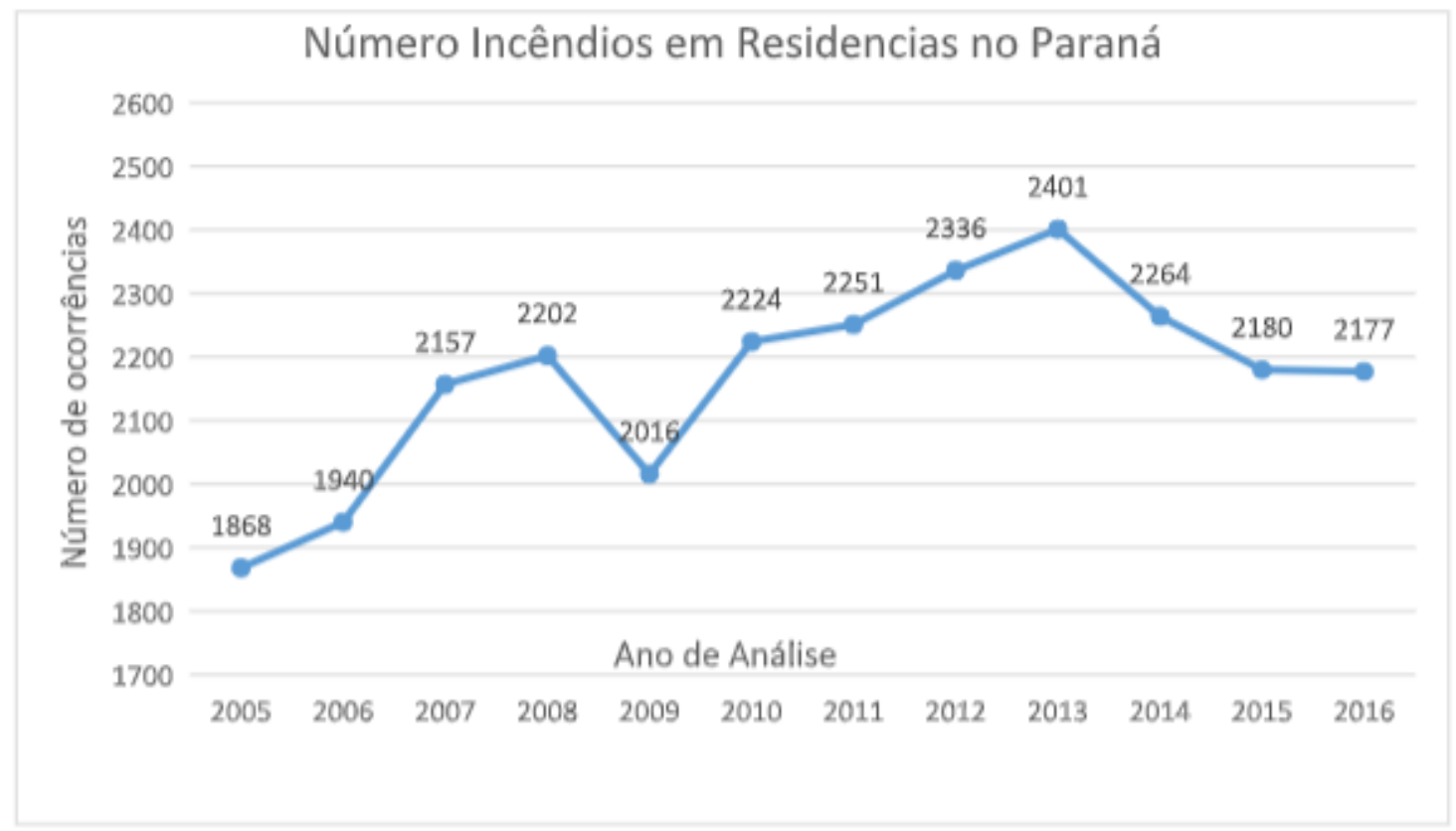

Fonte: SYSBM (2018).

Os primeiros dados coletados são os números de ocorrências em edificações residências térreas entre os anos de 2005 a 2016, como mostrado no Gráfico 1, nesse caso, pode-se observar que ela não segue uma tendência de aumento ou diminuição, ela varia de acordo com o ano e a quantidade de ocorrências registradas, sendo a média entre esses números de 2168 e com isso identificamos que varia $14 \%$ para mais ou para menos durante os anos 


\section{Revista FLAMMAE}

Revista Científica do Corpo de Bombeiros Militar de Pernambuco

Artigo publicado no Vol.05 Nº12 - Edição de JAN a JUN 2019 - ISSN 2359-4829

Versão on-line disponível em: http://www.revistaflammae.com.

tendo uma diferença de 533 casos entre os anos com maior e menor quantidade de casos.

Utilizando as ocorrências totais de incêndio em edificações ao longo dos anos, foi realizado um percentual comparando os casos em residências localizadas no pavimento térreo, e os demais registrados pelo corpo de bombeiro ao longo dos anos. As porcentagens obtidas em casos de residências, encontram-se entre $47,1 \%$ obtido em 2006 e 50,5\% obtidos em 2013, como observado no Gráfico 2, representando em média 49\% das ocorrências gerais, observando-se assim que todos os outros casos de incêndio registrados obtiveram uma média de $51 \%$.

Gráfico 2- Gráfico de porcentagem de ocorrências no Paraná entre 2005 e 2016.

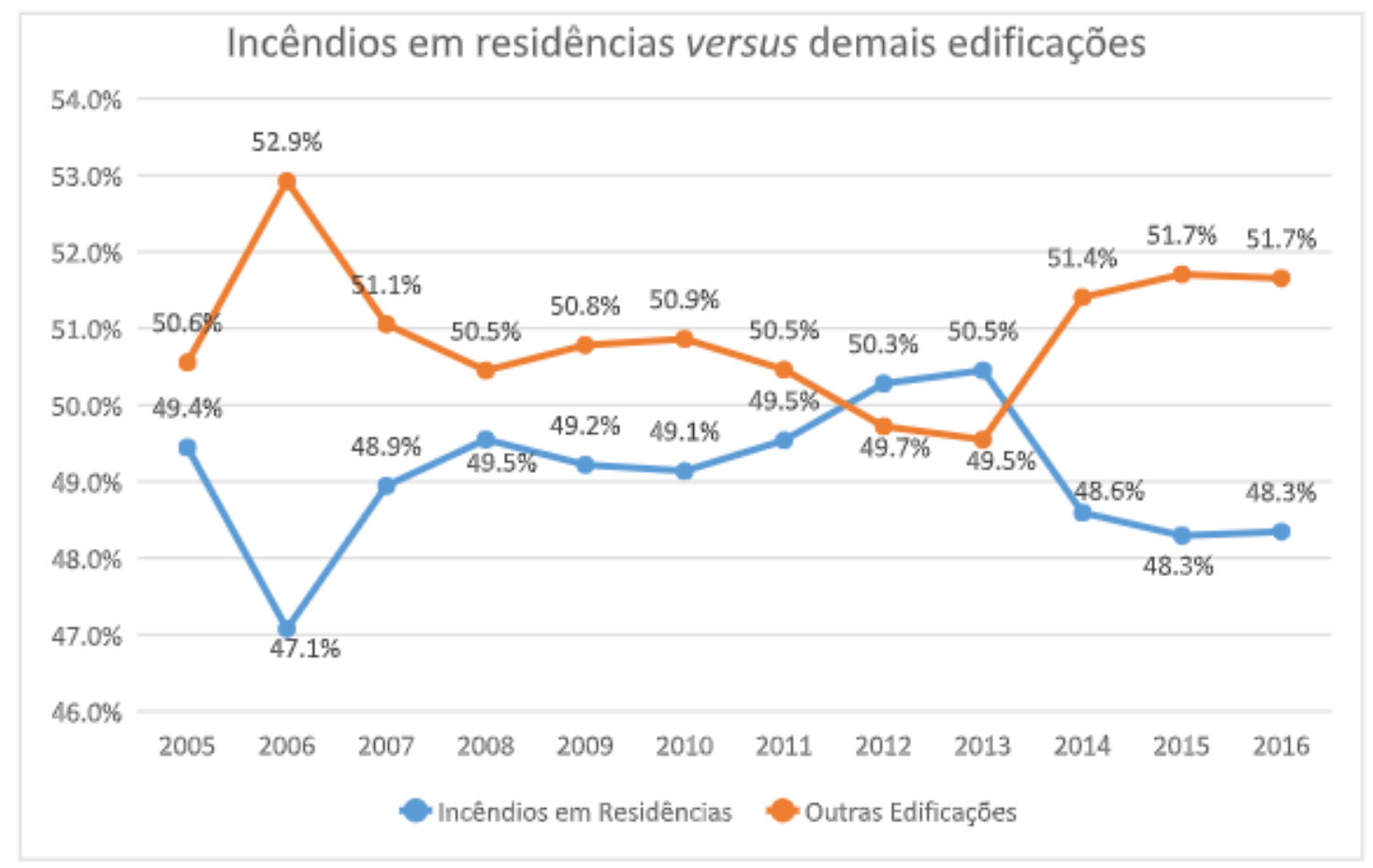

Fonte: Os autores (2018).

Outra análise realizada foi referente a quantidade óbitos em incêndios em todas as ocorrências registradas representadas no Gráfico 3. 
Revista Científica do Corpo de Bombeiros Militar de Pernambuco

Artigo publicado no Vol.05 Nº12 - Edição de JAN a JUN 2019 - ISSN 2359-4829

Versão on-line disponível em: http://www.revistaflammae.com.

Gráfico 3 - Quantidade de ocorrências total.

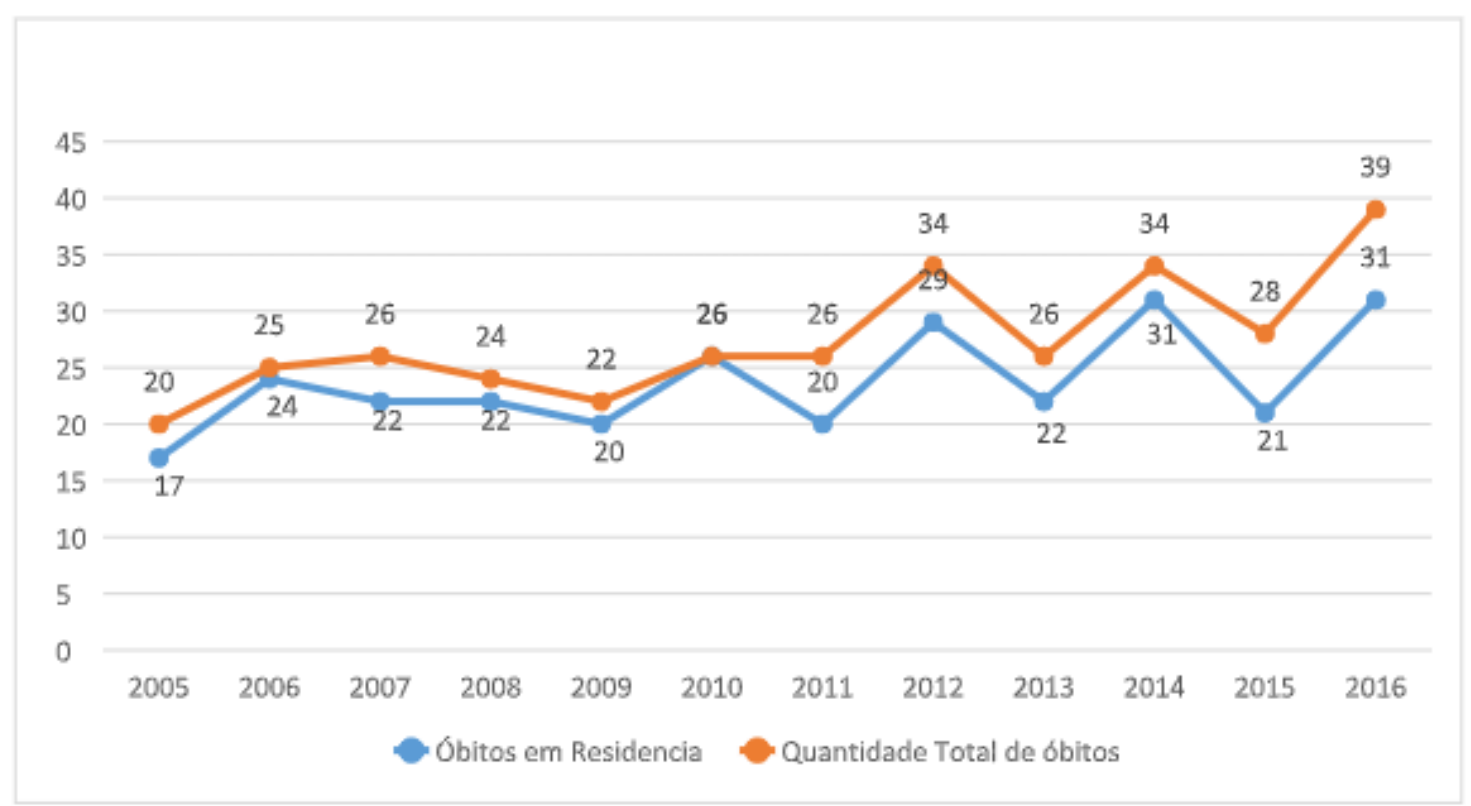

Fonte: Os autores (2018).

Os óbitos em edificações em geral estão definidas em faixas de 17 em 2005 e de 39 em 2016, apesar de não serem dados alarmantes em quantidade, quando comparadas ao número de mortes em residências torna-se visível a proximidade de números, quando no momento em que mais houve mortes em outros tipos de edificação foi em 2016, com 8 casos, Sendo assim, foi retirado as porcentagens desses valores para melhor analise, como mostrado no Gráfico 04. 
Revista Científica do Corpo de Bombeiros Militar de Pernambuco

Artigo publicado no Vol.05 Nº12 - Edição de JAN a JUN 2019 - ISSN 2359-4829

Versão on-line disponível em: http://www.revistaflammae.com.

Gráfico 4 - Gráfico da porcentagem de ocorrências de incêndio em residências.

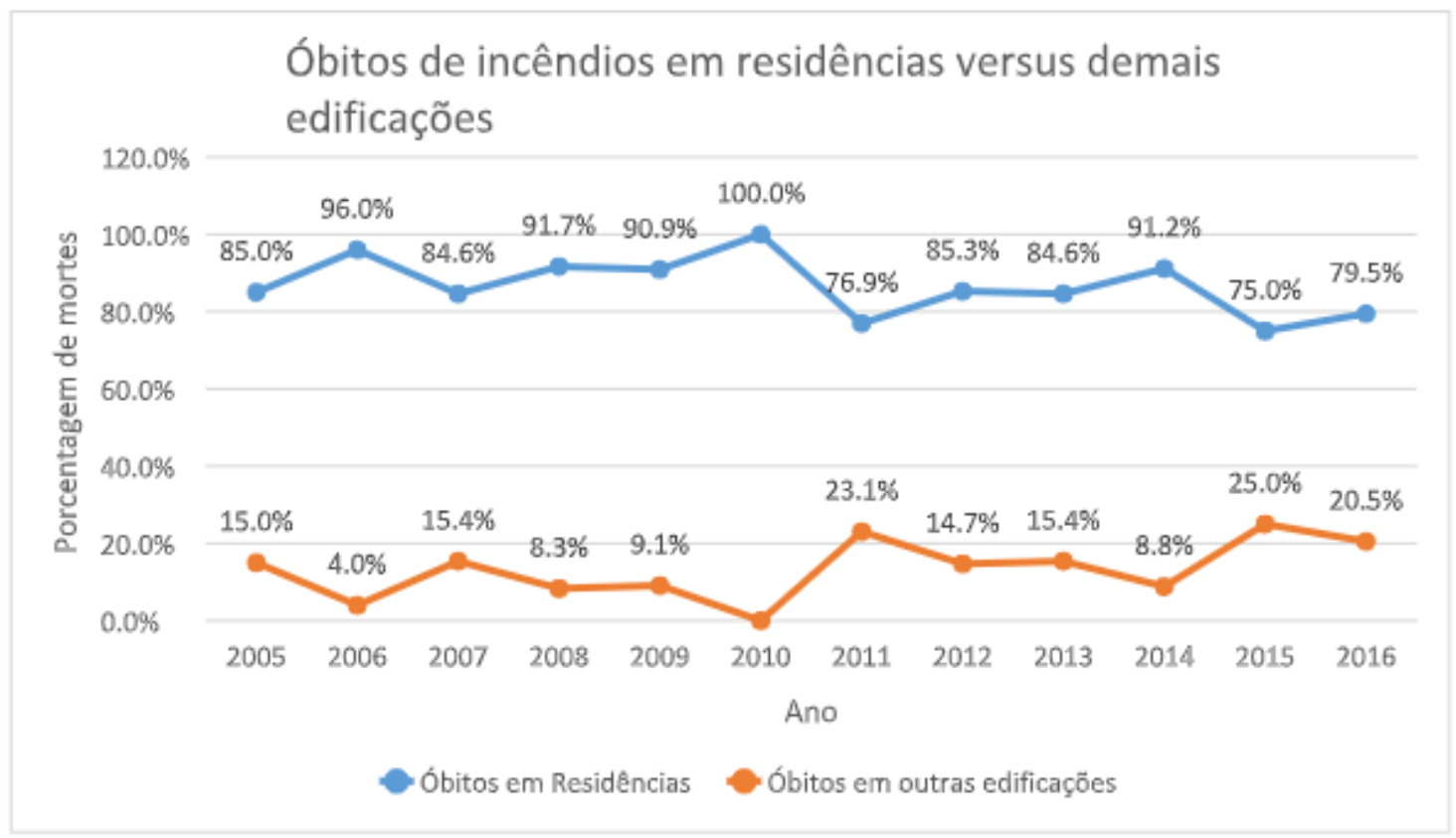

Fonte: Os autores (2018).

Quando observados as porcentagens dos óbitos em edificações, como na figura 4, as residenciais de pavimento térreo oscilam entre $75 \%$ em 2015 e $100 \%$ em 2010 , obtendo uma média de aproximadamente $87 \%$, o que nos traz uma porcentagem alta quando se observa somente um grupo separado de ocorrências, observando assim que, entre todos as outras ocorrências, as porcentagens se encontram entre $0 \%$ e $25 \%$.

No Gráfico 5 pode-se observar a relação entre a porcentagem de ocorrências de incêndio, e a porcentagem de mortes derivadas desses acontecimentos, onde se nota uma diferença surpreendente em porcentagens de incêndios gerais no estado do Paraná ao longo dos anos. 
Revista Científica do Corpo de Bombeiros Militar de Pernambuco

Artigo publicado no Vol.05 º12 - Edição de JAN a JUN 2019 - ISSN 2359-4829

Versão on-line disponível em: http://www.revistaflammae.com.

Gráfico 5 - Gráfico da porcentagem de ocorrências de incêndio em residências entre 2005 a 2016 e seus respectivos óbitos.

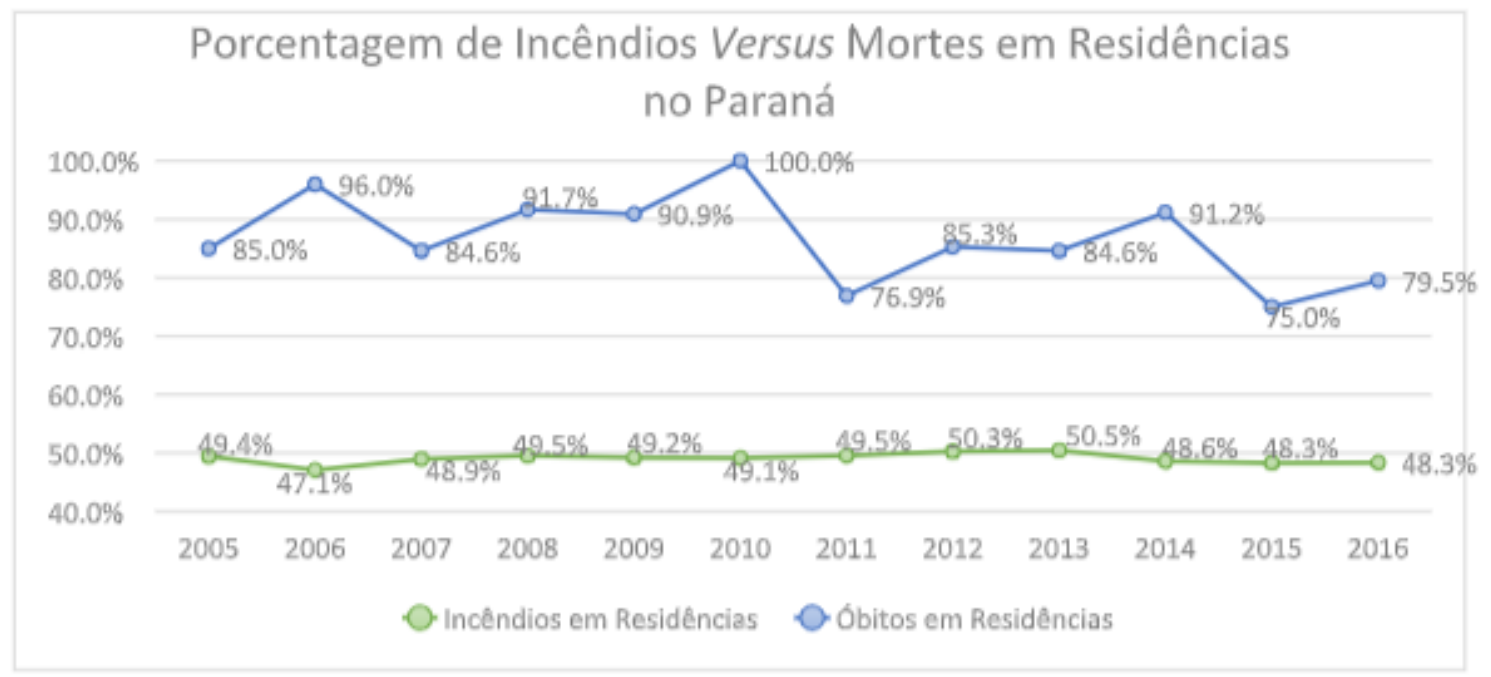

Fonte: Os autores (2018).

A quantidade de incêndios em edificações residenciais registrados pelo Corpo de Bombeiros do Paraná, quando observadas em porcentagem mostra uma diferença nas oscilações ao longo dos anos relativamente baixa, de 3,4\%, ficando aproximadamente de $50 \%$ em relação as demais, e apesar das fatalidades advindas das mesmas oscilarem em porcentagens relativamente maiores, os números também são maiores, obtendo-se uma média de $87 \%$.

\section{CONSIDERAÇÕES FINAIS}

Ao determinar a seriedade das perdas que ocorrem nos casos de incêndio em edificações, é de suma importância a análise de como ocorre, em quais tipos de edificações e o que se pode fazer para diminuir os riscos e melhorar a proteção da vida dos ocupantes das edificações.

Outra fonte importante de dados e leis a serem levados em consideração, são as de outros países, os quais apesar da grande ocorrência de incêndios, os casos de morte são significativamente menores que outros, como mostrado nas figuras 2 e 3 , onde, um dos exemplos a serem citados são 
Revista Científica do Corpo de Bombeiros Militar de Pernambuco

Artigo publicado no Vol.05 º12 - Edição de JAN a JUN 2019 - ISSN 2359-4829

Versão on-line disponível em: http://www.revistaflammae.com.

os Estados Unidos, que apesar de suas altas quantidades de incêndios por habitante comparado a outros países, tem um número consideravelmente menor em questões de mortes causadas por esses incidentes.

Isso nos traz a eficácia de suas leis de prevenção de incêndio sendo aplicadas corretamente não somente em locais com maiores perigos de incêndio ou de reunião de público, assim como em residências, mesmo sendo elas unifamiliares.

A ciência de prevenção de incêndio é pouco estudada no Brasil, como podemos ver um exemplo do pouco investimento em questões de acessos e registros de dados confiáveis a serem analisados, sendo o Paraná um exemplo a ser seguido em catalogação de dados reais e detalhados.

Ao analisar as estatísticas em relação as ocorrências nesses locais são alarmantes, tanto em questão de números, os quais apresentam uma média de 2.168 casos, como em porcentagem comparados aos demais casos estudados, apresentando uma média de 49\%. Entre todos os registros obtidos pelo Corpo de Bombeiros do Estado do Paraná no intervalo de 2005 a 2016, é extremamente preocupante o fato que, aproximadamente $50 \%$ dos casos estejam incluídos em somente um grupo de ocorrências, sendo ainda mais analisado se tratando de residências térreas.

Outro dado que permite muitas analises é a quantidade de óbitos em comparação as porcentagens de ocorrências remetendo-se assim, o Gráfico 04, sendo por exemplo, no ano em que a porcentagem de ocorrências em residências foi menor, em 2006, com 47,1\%, a porcentagem de óbitos nesses casos em comparação com os demais, obteve uma das maiores taxas, de $96 \%$. O ano de 2010 , em que se atingiu os $100 \%$ das mortes por incêndio em residências, a quantidade de ocorrência desses incêndios foi de $49,1 \%$, bem próximo da média geral.

As informações acima nos remetem a necessidade maior de se levar em consideração a realização de estudos e orientações construtivas que abranjam esse tipo de edificação apoiando-se nas grandes porcentagens de 
Revista Científica do Corpo de Bombeiros Militar de Pernambuco

Artigo publicado no Vol.05 º12 - Edição de JAN a JUN 2019 - ISSN 2359-4829

Versão on-line disponível em: http://www.revistaflammae.com.

mortes em edificações que estão isentas de quaisquer tipos de prevenção de incêndio ou métodos de proteção.

As normas de alguns estados dos Estados Unidos nos trazem itens como o sistema de detecção e alarme de incêndio e as saídas de emergência como obrigatórios em quaisquer tipos de residência, sendo medidas simples que podem ser instaladas ou adaptadas e que se comprovam eficazes nesse tipo de questão.

Os sistemas de detecção e alarme ainda são pouco comercializados no Brasil, sendo um custo relativamente alto para a instalação dos mesmos, mas ainda assim pode se tornar viável quando se tratar os casos de fogo em residências como algo sério e que precisa de cuidados.

Os acessos e saídas de emergência são de importância relativamente grande se tratando de ocorrências de incêndio no quesito cuidado com as vidas humanas existentes na edificação, sendo assim o cuidado ao projetar essas saídas das edificações pode ser de grande valia em casos de risco, principalmente ao se observar os números de mortes relacionadas a residências térreas.

Uma das soluções que podem ser implementadas, além das citadas acima, são cursos e maiores estudos para repassar para profissionais que estão projetando novas residências, alguns itens principais a serem priorizados para que, pelo menos os acessos e saídas possam ser eficazes nesses tipos de situação.

\section{REFERÊNCIAS}

ABOLINS, Cel Reserva PM Heliodoro Alexandre; BIANCHINI, Major PM Flavio José; NOMELLINI, 1ำ Tenente PM Luiz Henrique. Saídas de emergência em edificações. In: SEITO, Alexandre Itiu et al. A segurança contra incêndio no Brasil. 1. ed. São Paulo: Projeto Editora, 2008. p. 101-121.

ARAUJO, Major PM Carlos Henrique de; SILVA, Capitão PM Adilson Antonio da. Detecção e Alarme de incêndio. In: SEITO, Alexandre Itiu et al. A 
Revista Científica do Corpo de Bombeiros Militar de Pernambuco

Artigo publicado no Vol.05 º12 - Edição de JAN a JUN 2019 - ISSN 2359-4829

Versão on-line disponível em: http://www.revistaflammae.com.

segurança contra incêndio no Brasil. 1. ed. São Paulo: Projeto Editora, 2008. p. 201-213.

ASSOCIAÇÃO BRASILEIRA DE NORMAS TÉCNICAS. NBR 17240: Sistemas de detecção e alarme de incêndio - Projeto, instalação, comissionamento e manutenção de sistemas de detecção e alarme de incêndio Requisitos. Rio de Janeiro, p. 10. 2010.

CARLO, Ualfrido Del; A Segurança contra incêndio no Brasil. In: SEITO, Alexandre Itiu et al. A segurança contra incêndio no Brasil. 1. ed. São Paulo: Projeto Editora, 2008. p. 9-17.

CORPO DE BOMBEIROS CASCAVEL (SYSBM-CBB). Disponível em: $<$ http://www.bombeiroscascavel.com.br/registroccb/imprensa.php>. Acesso em: 03 de julho de 2018.

COUGHI, Ricardo de Scarabello. Aspectos de análise de risco das estruturas de concreto em situação de incêndio. 239 p. Dissertação (Mestrado em Engenharia)- Aspectos de análise de risco das estruturas de concreto em situação de incêndio, São Paulo, 2006.

CORREA, Cristiano; SILVA, José Jéferson do Rêgo; OLIVEIRA, Tiago Ancelmo de Carvalho Pires de; BRAGA, George Cajaty. Mapeamento de Incêndios em edificações: um estudo de caso na cidade de Recife. 2015. 20 p. Revista de Engenharia Civil IMED.

CSCIP. Código de Segurança Contra Incêndio e Pânico. Corpo De Bombeiros Do Estados Do Paraná. CSCIP. Paraná, 2015.

CTIF, International Association Of Fire And Rescue Services. World fire statistics: INTERNATIONAL RESIDENTIAL CODE. 22. ed. RUSSIA: CTIF, 2017. 56 p.

FAGUNDES, Fábio. Plano de prevenção e combate a incêndios: estudo de caso em edificação residencial multipavimentada. $71 \mathrm{p}$. Monografia (Curso de Pós Graduação Lato Sensu em Engenharia) - Universidade Regional Do Noroeste Do Estado Do Rio Grande Do Sul, Santa Rosa, 2013.

FIRE DEPARTMENT, Stratford. Fire prevention. Disponível em: $<$ https://www.stratfordcanada.ca/en/ivehere/fireprevention.asp>. Acesso em: 03 ago. 2018.

FREIRE, Carlos Darci da Rocha. Projeto de proteção contra incêndio (PPCI) de um prédio residencial no centro de Porto Alegre. Porto Alegre, RS, 2009.UFRS. 
GOMES, Taís. Projeto de prevenção e combate à incêndio. Santa Maria, RS, 2014. UFSM.

IRC. INTERNATIONAL CODE COUNCIL. INC. Washington State Building Code: INTERNATIONAL RESIDENTIAL CODE. USA: [s.n.], 2015. 1260 p.

MITIDIERI, Marcelo Luis. O comportamento dos materiais e componentes construtivos diante do fogo - reação ao fogo.. In: SEITO, Alexandre Itiu et al. A segurança contra incêndio no Brasil. 1. ed. São Paulo: Projeto Editora, 2008. p. $55-75$.

NBCC, National Building Code of Canada; Fire Safety in Residential Buildings. Canada: Building Performance Series: № 02, 2010. 12 p. Disponível em: $<$ http://cwc.ca/wp-content/uploads/publicationsP2_FireSafetyResidential.pdf>. Acesso em: 17 abr. 2018.

NFPA 5000: APPLYING Building Codes to Tiny Homes. Estados Unidos: [s.n.], 2017. 10 p. Disponível em: <https://www.nfpa.org/-/media/Files/Whitepapers/WhitePaperTinyHomes.pdf>. Acesso em: 03 ago. 2018

ONTÁRIO, CANADÁ. ONTÁRIO REGULATION n. 2013/07, de 03 de ago. de 2018. FIRE PROTECTION AND PREVENTION ACT. FIRE CODE. E-Laws, p. 129-145, maio. 2017.2 Disponível em: https://www.ontario.ca/laws/regulation/r07213>. Acesso em: 03 ago. 2018.

PARANÁ, NPT 011 Norma de Procedimento Técnico: Saídas de Emergência. Corpo de Bombeiros do Paraná, Curitiba: 2016.

UMINSKI, Alessandra S. de Carvalho. Técnicas de prevenção e combate a sinistros. Santa Maria, RS: Colégio Nossa senhora de Fátima, 2003. 